\title{
Review of Food Safety Policy in Nigeria
}

\author{
Augustine Okoruwa* Nwando Onuigbo-Chatta \\ Global Alliance for Improved Nutrition (GAIN) Nigeria, 37A Patrick O. Bokkor Crescent, Jabi, Abuja, Nigeria \\ Corresponding author email: aokoruwa@gainhealth.org
}

The research is financed by the generous support of the American people through the United States Agency for International Development (USAID) for the EatSafe: Evidence and Action Towards Safe, Nutritious Food project. Agreement Number: 7200AA19CA00010/

\section{Abstract}

Food safety is an integral part of food and nutrition security. Foodborne diseases (FBD) can occur when food safety measures are not applied. Unfortunately, most of the burden of foodborne illness is shouldered by children under five years of age and people living in low- and middle-income countries (LMIC). The foundation of food safety is built upon a quality-safety culture, compliance with food laws, regulation, policy, traceability, and food safety management systems encompassing documentation, training, auditing, reporting and corrective action. This paper reviews four existing national policy documents in Nigeria, three of which include food safety components. The fourth document, the National Policy on Food Safety and Its Implementation Strategy (NPFSIS), is Nigeria's principal food safety policy document and was reviewed in more detail. This review focuses on the situational and analytical concepts of the policy framework of the National Food Safety System (NFSS) in Nigeria. It also examines the status of the implementation of the NPFSIS 2014 and its alignment with international best practices. It was undertaken to assess existing food safety policy documents in Nigeria, identify gaps, make recommendations, and proffer solutions.

Keywords: food safety, policy, foodborne diseases, gaps, Nigeria

DOI: $10.7176 / \mathrm{JLPG} / 110-07$

Publication date:June $30^{\text {th }} 2021$

\section{Introduction}

In 2010 the global burden of foodborne disease (FBD) was estimated at 600 million illnesses and 420,000 premature deaths. Most of the burden of illness is shouldered by children under five years of age (38\%) and people living in low- and middle-income countries (53\%) (WHO 2015). The United Nations International Children Emergency Fund (UNICEF) also reported that diarrhea is a leading killer of children, accounting for approximately 8 per cent of all deaths among children under age 5 worldwide in 2017 (UNICEF 2019). This translates to over 1,300 young children dying each day, or about 480,000 children a year, despite the availability of simple effective treatment.

Food safety, defined as the assurance that food will not cause harm to the consumer when it is prepared or eaten according to its intended use (FAO/WHO 1997), is an integral part of food and nutrition security. Food safety systems can apply to private sector approaches to controlling food safety hazards within a food chain, or to businesses seeking to ensure that their food products are safe for consumption (FAO \& WHO 2007). This system encompasses the scientific discipline of handling, preparing, distribution and storage of food in a way that will prevent foodborne disease outbreaks and illnesses. Food safety involves not only the avoidance of foodborne pathogens, chemical toxicants, and physical hazards, but also nutrition, food quality, labeling, and education (IMNRC 1998). The foundation of food safety is built upon a quality-safety culture, compliance with food laws, regulation and policy, traceability and food safety management systems encompassing documentation, training, auditing and reporting, corrective action.

FBDs are common in Nigeria because of the prevailing poor food handling and sanitation practices, tokenistic and inadequate food safety laws, weak regulatory systems, lack of financial resources to invest in safer equipment and infrastructure, and a lack of education for food handlers (Ezirigwe 2018; Olalekan et al. 2019; Grace et al. 2018; Omojokun 2013, Ukwueze 2019). Food safety concerns in Nigeria include biological, physical and chemical contamination, adulteration, misbranding, aflatoxin contamination, illegal food trading, and weak control over imported and exported foods (Ezirigwe 2018; Olalekan et al. 2019; Grace et al. 2018; Omojokun 2013). Poor food hygiene and limited oversight along the value chain leads to widespread FBD: there are an estimated 173 million cases of diarrhea caused by foodborne illness annually in Nigeria, and about 33,000 deaths from these illnesses (Grace et al. 2018). The costs of treating these illnesses are estimated at USD 1.7 billion annually - with a considerably larger economic toll if the cost of lost labor and productivity are considered (Grace et al. 2018).

Nigerian food safety policy sets out the principles, values, priorities, and strategies necessary to enable the development of actions to address the main concerns of the sector. In order to advance food safety in Nigeria, it requires a robust, comprehensive and sustainable food safety interconnected system with coherent national food 
safety policies and strategic action plans. However, the food safety policy situation in Nigeria has not been moving in the expected direction despite efforts of policy redress over the years including the formulation of the NPFSIS in 2014. NPFSIS 2014 can be regarded as Nigeria's master road map and action plan on food safety.

Nigeria's agricultural sector is a major producer of food and industrial products. In order to ensure the quality of food produced and sold, the national food safety system is important to regulating and enforcing food safety laws and standards in line with international best practices. Nigeria, as a member of the United Nations (UN) and signatory to all Conventions and Declarations on Health, Agriculture, Environment and Trade, is committed to meeting international food safety requirements. Improving food safety and protecting the health of Nigeria's citizens would be enhanced via the enactment of food legislation. While the regulation, control, monitoring and evaluation of food safety in Nigeria was described in the NPFSIS 2014 policy document, legislation is needed to implement this policy. Review of the national policy has disclosed challenging issues in the areas of communication, collaboration, cooperation and funding among stakeholders and MDAs. It also described the emerging adoption of poor eating habits, poor food hygiene awareness and poor food handling practices due to an increase in the number of MSMEs due to urbanization. Thus, the need for a robust and functional food safety policy in Nigeria is imperative and urgent.

A food safety policy provides the framework for the establishment of national food safety objectives and requirements and offers guidance for application to specific sectors of the food supply chain (production, processing, storage, transportation and marketing). Nigeria's food safety policy sets out the principles, values, priorities, and strategies necessary to address the main concerns of the sector. Advancing food safety in Nigeria requires a comprehensive and sustainable system with coherent national food safety policies and strategic action plans. However, food safety policy in Nigeria has not developed in the expected direction despite efforts of redress over the years, including the formulation of the NPFSIS in 2014 . NPFSIS 2014 can be regarded as Nigeria's master road map and action plan on food safety. The national food safety system is important in regulating and enforcing food safety laws and standards in line with international best practices. In addition, Nigeria, as a member of the United Nations (UN) and signatory to all Conventions and Declarations on Health, Agriculture, Environment and Trade, is committed to meeting international food safety requirements.

While the regulation, control, monitoring and evaluation of food safety in Nigeria was described in the NPFSIS 2014 policy document, legislation is needed to implement the Policy. Review of the national Policy has disclosed challenging issues in the areas of collaboration and funding among stakeholders and the responsible Government Ministries, Departments and Agencies (MDAs). In addition, poor eating habits, poor food hygiene awareness and poor food handling practices attributed to increases in urbanization and the number of Micro, Small and Medium Enterprises (MSMEs) is a challenge. Therefore, the need for a robust and functional food safety policy in Nigeria and its effective implementation is imperative and urgent.

The purpose of this review was to assess the content, scope, structure, and institutional landscape of existing food safety policy; identify gaps in the food NPFSIS; and recommend improvements in both the policy and its implementation. This review focuses on the situational and analytical concepts of the policy framework of the National Food Safety System (NFSS) in Nigeria and examines the status of the implementation of the NPFSIS 2014 and its alignment with international best practices. This review further underscores the objectives at the conception of NPFSIS; tracks the policy landscape and institutional structures for food safety in Nigeria; and identifies gaps and suggests modifications to improve and enhance the completeness and implementation of NPFSIS 2014.

The review methodology comprised a desk review of the four relevant policy documents as published by the various Ministries, Departments and Agencies (MDAs) in Nigeria. Those documents were reviewed against international and regional documents on food safety policies, food control and food safety systems, and implementation strategies obtained through internet searches. Those resources provided benchmarks for best global practice in food safety policy and implementation. International resources included reports and publications on food safety issues, such as peer-reviewed papers, project reports, international and global food safety expert publications and media reports that could be accessed online and/or downloaded and reviewed, consistent with the objective of the review. Limited telephone calls were also used to gather information from relevant stakeholders.

The paper is divided into four parts: introduction, review of national policy documents with food safety components, review of the National Policy on Food Safety and its Implementation Strategy (NPFSIS 2014), and Conclusion.

\section{National Policy Documents with Food Safety Components}

In Nigeria, multiple government bodies play a role in ensuring the safety of foods along the farm to table continuum. The policies government actors implement are directed at farm production, safe food processing, consumer health protection, food standards, preservation of the environment, and regulations to meet safety and quality requirements in international trade. The national policies with food safety components are listed below: 
1. The Agriculture Promotion Policy (2015-2020) of the Federal Ministry of Agriculture and Rural Development (FMARD)

2. The National Food and Nutrition Policy (2016) of the Ministry of Budget and National Planning (MBNP)

3. The National Policy on the Environment (Revised 2016) of the Federal Ministry of Environment (FME)

4. The National Policy on Food Safety and Its Implementation Strategy (NPFSIS 2014) of the Federal Ministry of Health (FMOH)

It should be noted that the first three policies above are not food safety policy documents per se, but mainly sectorial policy documents focused on agriculture, food and nutrition, and the environment, with only small sections addressing food safety and health. Therefore, the policies were not individually evaluated for food safety comprehensiveness. The NPFSIS, however, outlined the policy and implementation strategies that would improve food safety oversight and drive its effectiveness. Thus, NPFSIS 2014 is the central food safety policy document reviewed in detail in this review. It was examined in detail according to the following 9 areas: scope, institutional arrangement, policy targets, merits, gaps and limitations, implementation strategy, monitoring and evaluation, sustainability and policy modification.

2.1 The Agriculture Promotion Policy (2016-2020)

The Federal Ministry of Agriculture and Rural Development (FMARD) has an important role to play in food safety. Its Nutrition and Food Safety Division is dedicated to this purpose. The goal of the Agriculture Promotion Policy (APP) (FMARD 2016-2020) was aimed at building a high-quality brand for Nigerian foods based on rigorous data and processes that protect food safety for both domestic and export market consumers. One of the specific objectives is building the government's capacity to meet its obligations to Nigerians in food security, food safety and quality nutrition. Thus, FMARD's Agriculture Sector Food Security and Nutrition Strategy (ASFSNS, 2016-2025) was developed to support the APP goals. The Strategy has eight inter-related priority areas, one of which is focused on improving food safety along the value chain. The APP provided for programs and activities to introduce and enforce quality standards for inspection, grading, food safety and traceability for both large and small-scale growers. FMARD also recognized to submit, in coordination with the Federal Ministry of Health, the Food Safety and Quality Bill to the National Assembly for legislation. Even though the APP emphasizes the coordination of efforts between concerned government bodies to improve efficiency, it still fails to address some important aspects of a strong food control system; such as laboratory services, Information, Education, Communication (IEC), and Training, that are included in the FAO/WHO Guidelines on Strengthening National Food Control Systems. This is not surprising as the policy was not designed as a food safety policy document.

\subsection{National Food and Nutrition Policy}

In 1990, a National Committee on Food and Nutrition (NCFN) was set up in the then Federal Ministry of Science and Technology (FMST) to formulate a National Food and Nutrition Policy. This mandate was later transferred to the Federal Ministry of Health (FMOH) in 1993. However, in 1994 the NCFN and emerging programs were relocated to the National Planning Commission (NPC), now known as the Ministry of Budget and National Planning (MBNP), because of its unique position as the government agency responsible for coordination, budgeting and monitoring of all national policies and programs related to food and nutrition. The National Food and Nutrition Policy (NFNP) provides the framework for addressing the problems of food and nutrition insecurity in Nigeria at the individual, household, community and national levels. It guides the identification, design, and implementation of intervention activities across relevant sectors. The National Food and Nutrition Policy recognizes the importance of promoting food safety during production, processing and storage while addressing the issue of availability, accessibility, and affordability of food. It promotes the development and enforcement of minimum standards for food quality and safety both for imported and locally produced foods, including street-vended foods. This includes strengthening the mechanisms for detection, monitoring, and control of chemical residues in foods.

Even though the policy scored well when evaluated against the FAO/WHO Guidelines on Strengthening National Food Control Systems, it did not emphasize food safety training for control system enforcement by agency personnel as prioritized by FAO/WHO guidelines on Assuring Food Safety and Quality (FAO \& WHO 2003). Therefore, this should be considered during the policy's next revision in order to help achieve the national food safety objectives.

\subsection{National Policy on the Environment}

The National Policy on the Environment (FME 2016) recognizes that environmental pollution has grown considerably in Nigeria. With the advent of modern agricultural production, farmers have increasingly relied on chemical inputs, such as herbicides and pesticides, which pose great concerns about environmental health. The pollution of air, water and soil comes from extensive use of fertilizers on farms, dumping of expired and 
contraband chemicals and pesticides in the country, and improper storage and handling of chemicals. Policy statements relating to food safety in the National Policy on the Environment indicate that the government will manage and control farmers' reliance on artificial inputs, including herbicides and pesticides that are harmful to the environment. In order to provide the desired effect of these statements, we recommend that a national pesticide policy in Nigeria prohibit the use of banned chemicals globally and specify approved chemicals and limits of use for the production and storage of food products, especially legume and cereal grains. In addition, the Policy should also prohibit the use of hazardous chemicals to harvest and preserve fish as practiced by some artisanal fish farmers and aquaculture farmers.

\section{The National Policy on Food Safety and its Implementation Strategy (NPFSIS 2014)}

The NPFSIS was drafted in 2014 by the Federal Ministry of Health (FMOH) and is Nigeria's most comprehensive food safety policy document. Its implementation was to be supported by a Food Safety \& Quality Bill to be introduced as legislation. However, the Food Safety and Quality Bill (2016) is still awaiting enactment into law by the National Assembly almost four years after it was drafted - a major setback for NPFISIS 2014. The Bill would give legal, budget, and enforcement authority to the policy when passed into law. One measure of the quality and comprehensiveness of a food safety policy is how well it aligns with the building blocks for Strengthening National Food Control Systems as outlined in the FAO/WHO guidelines on Assuring Food Safety and Quality (FAO \& WHO 2003). A review of the NPFSIS 2014 showed that it encompasses all the components known to strengthen national food safety systems, including Food Law and Regulations; Food Control Management; Inspection Services; Laboratory Services; Food Monitoring \& Epidemiological Data and Information, Education, Communication and Training. The policy consists of four chapters: Policy Framework, Institutional Arrangement, Implementation Strategies, Monitoring and Evaluation. The policy also identifies the roles of both public and private bodies relevant in food safety, including farmers, processors, professional bodies, private laboratories, the academia and research institutes.

NPFSIS 2014 aims to integrate and harmonize all existing laws, standards and codes that regulate food safety practices in Nigeria, redefine and coordinate existing food control infrastructures at various levels of government and reduce areas of overlap and conflict. It is widely felt by thought leaders and practitioners that the implementation of the policy would minimize foodborne disease outbreaks attributed to poor safety practices and reduce the overall prevalence of foodborne illness. The policy is predicated on the adoption of Hazard Analysis and Critical Control Point (HACCP) system principles during the preparation, production, handling, storage, processing/preservation, transportation, and distribution of foods. It recognizes that food safety in the agricultural sector begins with risks associated with the inputs to agricultural production, such as pesticides, fertilizers and veterinary drugs.

\subsection{Scope}

NPFSIS 2014 provides a framework for the identification of national food safety objectives and the formulation of suitable laws, regulations and guidelines aimed at achieving international best practices in all sectors of the food supply chain. It also establishes an early warning system to detect, trace and prevent outbreaks of foodborne illnesses before they spread. NPFSIS 2014 outlines a food safety mandate in Nigeria spread among 13 Ministries, Departments \& Agencies (MDAs). It also articulates roles of the State Ministries and the Local Government Areas (LGA) in reaching the nation's majority rural population. The MDAs are included table 1.

\subsection{Institutional Arrangement}

The government's objective in producing the NPFSIS 2014 policy document was to achieve a comprehensive, effective collaboration and coordination of nationwide, farm-to-table food safety practices through the adoption of an integrated food safety management system approach. Towards this end, the NPFSIS established the National Food Safety Management Committee (NFSMC) as the entity that coordinates the NFSS. Previous implementation strategies had been mostly sectorial in nature, generally uncoordinated, inadequately funded and limited in scope and did not achieve the desired outcomes. The Policy provides for an Inter-Ministerial Committee on Food Safety (IMCFS) to oversee the NFSMC with its functions clearly described. The IMCFS consists of five Honorable Federal Ministers of Health; Industry, Trade and Investment; Agriculture and Rural Development; Science and Technology and Environment (see figure 1). NPFSIS provides for the establishment of a thirty-one-member National Food Safety Management Committee (NFSMC) by the IMCFS consisting of the relevant MDAs, the private sector, research institutes, food professional bodies, public analysts and trade groups to implement the NPFSIS and to report to the IMCFS. The NPFSIS manages the relationship between Nigeria's national regulatory agencies and various international standards organizations, such as the Codex Alimentarius Commission (CAC), World Organization for Animal Health (OIE), International Plant Protection Convention (IPPC) and the Sanitary and Phytosanitary (SPS) Committee of the World Trade Organization. 
3.3 Policy Targets

NPFSIS 2014 outlined succinctly defined targets in tandem with international practice and guidelines. Partial achievement of the policy targets was realized through the adoption of the 2014 NPFSIS and inauguration of the National Food Safety Management Committee (NFSMC), marginal reduction in foodborne disease outbreaks, and some improvements in the safety of imported and exported food products. However, targets remain unfulfilled with respect to coordination of food control infrastructure, reduced food wastage, increased food security, and the adoption of food safety management systems such as HACCP. The public-private stakeholders' partnership and interface has not been effective and the unspecified targets for food safety education and communication have been of limited success.

\subsection{Merits}

This review noted the importance of the development of the National Policy on Food Safety and Its Implementation Strategy (NPFSIS) in 2014 by the Federal Ministry of Health. The document can be generally regarded as a successful exercise with a positive outcome in the drafting of a Food Safety \& Quality Bill for Nigeria in 2016 (FSQB). The NPFSIS 2014 is seen as a comprehensive document with clearly defined goals and roles of the stakeholders along the farm to table continuum of the food chain. The NPFSIS articulated the government's commitment to ensure that the public has access to safe, nutritious food and to comply with international best practices. It also sets a target for reducing foodborne illness by about $30 \%$ within five years of policy implementation. The NPFSIS 2014 adopted an integrated food safety management system approach, resulting in the establishment of a National Food Safety Management Committee (NFSMC) to coordinate the entirety of National Food Safety System (NFSS). The Inter-ministerial Committee on Food Safety (IMCFS) has its secretariat domiciled in NAFDAC and oversees the activities of the National Food Safety Management Committee (NFSMC), in coordination with FMOH, FMARD, FME, FMITI, and FMST. NPFSIS 2014 identified specific challenges with the previous policy implementation strategies, such as uncoordinated MDAs and stakeholders, inadequate funding and limited scope, which were obstacles to the achievement of desired outcomes. We observed that some of the problems listed above are also affecting the effective implementation of NPFSIS 2014. NPPFIS 2014 was planned for a 5-year implementation period during 2014-2019. As at the time of this report, the policy document is due for review and implementation has not been effected.

\subsection{Gaps and Limitations of the NPFSIS}

There are limitations on the ability of the Ministry and associated agencies to fulfill their roles and responsibilities within the NPFSIS. These include an incomplete grasp of the issues associated with fake drugs, expired foods, food ingredient labelling, certification, unwholesome processed food and the registration of food, drugs, and related products. There are also unresolved issues connected with inadequate information and a paucity of data on food safety in Nigeria. Most statistical information on disease outbreaks has actually been provided by the international community (WHO, FAO, UNICEF, World Bank, etc.). In relation to the above, the WHO had earlier lamented the few studies on foodborne diarrhea cases in developing countries (UNICEF 2020), including Nigeria. Coordination is lacking between Federal, State and Local governments on the performance of related tasks and responsibilities at each level. Unfortunately, regulatory enforcement seems to emphasize compliance with the meat, hide and skin regulation laws at the expense of seed and crop control regulations. The lack of modern infrastructure, facilities, professional expertise, and experience with modernized agricultural practices increases Nigeria's dependence on imported agricultural produce.

\subsection{Implementation Strategy of the Food Safety Policy}

The goal of the Nigerian government in developing the National Policy on Food Safety and Implementation Strategy (NPFSIS) 2014 was to achieve a comprehensive and effective program. NPFSIS 2014 (chapter 3 section 3.5) aimed to minimize the risk of foodborne disease outbreaks emanating from poor food safety practices and attain at least a 30\% reduction in the prevalence of foodborne and related diseases within the first five years of its implementation. Unfortunately, there is a lack of data with which to evaluate whether this has been achieved. In the absence of a single legal framework, the implementation of the food safety system rests with the MDAs/stakeholders at the three levels of the Nigerian government. Public-private sector partnerships coordinate food control infrastructure and help reduce functionality overlaps but can also complicate the implementation strategy. Despite NPFSIS 2014's comprehensive implementation strategy structure and mandates (Section 3.2-3.4), the inter-ministerial food safety committee approach still led to overlapping roles and a duplication of functions. We can assert that the implementation strategy of NPFIS has mostly not been achieved based on evidence on the ground. It is particularly discouraging to note that the Food Safety and Quality Bill (HB1598) had not been enacted into law before the first phase of NPFIS expired. 
3.7 Food Safety System Monitoring and Evaluation

NPFSIS 2014 entrusts food policy monitoring and evaluation to the Federal Ministry of Health (FMOH). Its two main agencies, the National Agency for Food and Drug Administration and Control (NAFDAC) and the National Primary Health Care Development Agency (NPHCDA), are required to collaborate with sister agencies and stakeholders. Chapter four of NPFSIS 2014 outlined a systematic monitoring measure to be executed by NFSMC and IMFSC over 1-2 years while the FMOH coordinates the broader evaluation of conformance with the national food safety implementation plan every three years in conjunction with key MDAs and stakeholders., While this monitoring and evaluation facilitates collaboration, there remains a need to develop a master monitoring plan and measures in an updated NPFSIS document.

\subsection{Sustainability of the Food Safety Policy in Nigeria}

Some of the major sustainability issues of NPFSIS 2014 are identified in the section on policy challenges and limitations. Food safety remains a major issue in Nigeria. Nigeria's case is worsened by public unawareness, a lack of adequate food safety training throughout the food supply chain, poor coordination of the food control system, lack of technical expertise, inadequate analytical laboratories, poor enforcement of food safety legislation by regulatory agencies, and an inadequate inspection and surveillance system that too often fails to prevent adulterated food from reaching the marketplace. (Ezirigwe 2018; Olalekan et al. 2019; Grace et al 2018; Omojokun 2013; Okonkwo \& Okonkwo 1980; Ukwueze 2019)). Due to the issues stated above, there is need to redouble efforts to implement NPFSIS 2014 facilitate in accordance with $2005 \mathrm{FAO} / \mathrm{WHO}$ recommendations. Improved policy guidance, technical assistance, infrastructure and partnership opportunities with donor agencies, NGOs, the private sector and the public can help improve food access, quality, standards and food safety and security (Olalekan et al. 2019; Grace et al 2018; Omojokun 2013). Furthermore, all levels of government should pursue their mandates holistically through the coordinated implementation of food safety policies (especially at the local government level where compliance and monitoring of food safety practices at the grass root level is key).

\subsection{Considerations for Policy Modification of NPFSIS 2014}

Based on the review of the NPFSIS 2014 document, the following modifications may facilitate more effective implementation, especially in the updated and revised version that is expected. Firstly, Chapter 2 Section $2.1 \mathrm{c}$, the Statement of Institutional Objectives, should engages private sector stakeholders to take greater responsibility in food safety and agricultural health as major actors rather than passive participants (being invited by NFSMC when needed), especially in policy making and execution. Secondly, the scope and effect of agricultural acts and laws of the policy document are inadequate in the areas of food regulation, production, storage, processing, certification, monitoring, distribution and trade. Therefore, responsible ministries should propose more proscriptive laws and enabling acts in these areas. Thirdly, this policy should be geared to promote public health and the adoption of international standards, especially at the rural sector level. This will help to reduce the incidence of foodborne illness and lower the mortality and morbidity rate among vulnerable groups (especially women and children). Lastly, lapses in the implementation of NPFSIS 2014 can be attributed to the still undeveloped master action plan; therefore, it is very important to develop a master action plan that outlines the implementation process at all levels of the government-Federal, State and Local Government Area Councils.

\section{Conclusion}

This review suggests that Nigeria's food safety policy should be revised to accommodate updated practices while decentralizing the channels of policy execution and implementation. This could be facilitated through the publicprivate interface and by active collaboration with international development and donor agencies on food safety matters generally and in the formulation and implementation of a revised policy document.

At present, there is confusion in areas of mandates and roles, and this could improve through a clear definition of roles and responsibilities with an objective target to carry all relevant sectors of the government along while limiting to the barest minimum inhibiting factors such as equivocal policy statements, and political factors. The proposed policy revision should champion new funding mechanisms for NPFSIS to limit the financial hurdles.

In areas of coordination, monitoring and control of the food safety system, a decentralization of primary MDAs to sub-MDAs should be facilitated to reduce the execution burden on NAFDAC and NPHCDA. The National Assembly should enact the Food Safety and Quality Bill (2016) into law as a matter of national importance. As the bill's suspended status in the National Assembly is a huge setback to the advancement of the food safety and control system in Nigeria. The eventual public hearing on the bill provides an opportunity for stakeholders to recommend updates and amendments to the proposed legislation since the bill's original drafting is now over four years old. The opportunity for amendments can be harnessed during the public hearing where concerned stakeholders can make additional input into the content of the bill. This will achieve the specific 
objective of supporting the implementation of the National Policy on Food Safety and Its Implementation Strategy and lead to sustainable improvements in national food safety and food security. Passage of the bill will also facilitate new food safety \& quality activities under the same umbrella body. This would improve effectiveness and efficiency arising from operations as a single unit rather than the current situation which presents some bureaucratic bottlenecks and inefficiencies.

\section{References}

Ezirigwe, J. (2018). Much ado about food safety: Implications in Nigeria. Afe Babalola University. Journal of Sustainable Development Law and Policy, Vol. 9

FAO/WHO, (1997), Codex Alimentarius Guidelines for the Design, Operation, Assessment and Accreditation of Food Import and Export Inspection and Certification Systems, (CAC/GL 26-1997). FAO/WHO, Rome.

FAO \& WHO, (2007), FAO/WHO guidance to governments on the application of HACCP in a small and/or less developed food businesses, FAO Food and Nutrition Paper 86. ISSN: 0254-4725. Geneva: Department of Food Safety and Zoonoses, WHO.

FAO \& WHO, (2003), Assuring Food Safety and Quality: Guidelines for Strengthening National Food Control Systems, FAO Food and Nutrition Paper 76, ISBN 92-5-104918-1.

Federal Ministry of Agriculture and Rural Development (FMARD), (2016-2020), The Agricultural Promotion Policy.

Federal Ministry of Environment (FME), (2016), National Policy on the Environment.

Federal Ministry of Health (FMOH), (2014), The National Policy on Food Safety and Its Implementation Strategy.

Grace, D. et al, (2018), Food safety investment expert advice, Burkina Faso, Ethiopia, Nigeria. Nairobi: ILRI.

Institute of Medicine National Research Council (IMNRC), (1998), Ensuring Safe Food from Production to Consumption. National Academy Press Washington, D.C.

Ministry of Budget and National Planning (MBNP), (2016), National Food and Nutrition Policy.

Okonkwo, C.O \& Okonkwo, N. (1980), Criminal Law in Nigeria, 2nd ed. Ibadan: Spectrum Books Ltd.

Olalekan, R.M. et al. (2019), Assessment of Environmental Sanitation, Food Safety Knowledge, Handling Practice among Food Handlers of Bukateria Complexes in Iju Town, Akure North of Ondo-State, Nigeria, Acta Scientific Nutritional Health 3.6: 186-200.

Omojokun, J. (2013), Regulation and Enforcement of Legislation on Food Safety in Nigeria, Mycotoxin and Food Safety in Developing Countries. Available from: http://dx.doi.org/10.5772/54423 [Accessed 15 July 2020].

Ukwueze, F.O. (2019). Evaluation of food safety and Quality regulations in Nigeria. Journal of Law, Policy and Globalization: Vol.92 https://www.iiste.org/Journals/index.php/JLPG/article/view/50924

UNICEF, (2019), Diarrhoeal disease data. https://data.unicef.org/topic/child-health/diarrhoeal-disease/ [Accessed 15 July 2020].

WHO, (2015), Estimates of the global burden of foodborne diseases. Geneva, Switzerland: World Health Organization. https://www.who.int/foodsafety/publications/foodborne_disease/fergreport/en/ [Accessed 15 July 2020].

Augustine E. Okoruwa (M'92-F'20) became a Member (MNIFST) of Association Nigerian Institute of Food Science and Technology in 1992, and a Fellow (FNIFST) in 2020. He was born in Eidenu-Irrua, Edo State, Nigeria on 1st August, 1962. He is a Food Technologist with the following degrees: Both Doctor of Philosophy (PhD) in food technology in 2005 \& Master's Degree in food technology in 1990 from University of Ibadan, Oyo State, Nigeria and Bachelor of Science Degree in Food Science and Technology was obtained from the University of Jos, Makurdi Campus, Nigeria in 1986 (now Federal University of Agriculture, Makurdi, Benue State, Nigeria).

Nwando O. Onuigbo-Chatta (M'06) Nwando became a Member (M) of Association Veterinary Council of Nigeria in 2006. She was born in Zaria, Kaduna State, Nigeria on 7th March, 1981. She is a Veterinary Doctor with the following degrees: Doctor of Veterinary Medicine (DVM) from Ahmadu Bello University (ABU) Zaria, Kaduna state in Nigeria, 2006. While her Master of Veterinary Public Health (MVPH) was from University of Glasgow, Glasgow in United Kingdom, 2011. 
Table 1: Breakdown of MDAs and policy documents related to Food Safety

\begin{tabular}{|c|c|c|c|c|c|}
\hline $\mathbf{S} / \mathbf{N}$ & $\begin{array}{l}\text { Federal } \\
\text { Ministry }\end{array}$ & Department & Agency & Policy Document & Comments \\
\hline \multirow[t]{2}{*}{1} & \multirow[t]{2}{*}{$\begin{array}{l}\text { Health } \\
\text { (FMOH) }\end{array}$} & $\begin{array}{l}\text { Directorate of } \\
\text { Food Safety \& } \\
\text { Applied } \\
\text { Nutrition } \\
\text { (FSAN) }\end{array}$ & $\begin{array}{l}\text { National Agency } \\
\text { for Food and Drug } \\
\text { Administration and } \\
\text { Control (NAFDAC) }\end{array}$ & $\begin{array}{l}\text { The National } \\
\text { Policy on Food } \\
\text { Safety and Its } \\
\text { Implementation } \\
\text { Strategy (2014) }\end{array}$ & $\begin{array}{l}\text { The following are } \\
\text { outcomes of the NPFSIS: } \\
\text { 1. The Inter-ministerial } \\
\text { Committee on Food } \\
\text { Safety (IMCFS) } \\
\text { 2. The National Food } \\
\text { Safety Management } \\
\text { Committee (NFSMC). } \\
\text { 3.The Food Safety and } \\
\text { Quality Bill (FSQB) }\end{array}$ \\
\hline & & $\begin{array}{l}\text { National Codex } \\
\text { Committee } \\
\text { (NCC). }\end{array}$ & $\begin{array}{l}\text { National Primary } \\
\text { Health Care } \\
\text { Development } \\
\text { Agency } \\
\text { (NPHCDA) }\end{array}$ & & \\
\hline \multirow[t]{2}{*}{2} & \multirow[t]{2}{*}{$\begin{array}{l}\text { Agriculture } \\
\text { and Rural } \\
\text { Development } \\
\text { (FMARD) }\end{array}$} & $\begin{array}{l}\text { Federal } \\
\text { Department of } \\
\text { Fisheries }\end{array}$ & $\begin{array}{l}\text { Nigeria } \\
\text { Agricultural } \\
\text { Quarantine Service } \\
\text { (NAQS) }\end{array}$ & \multirow[t]{2}{*}{$\begin{array}{l}\text { The Agriculture } \\
\text { Promotion Policy } \\
(2015-2020)\end{array}$} & $\begin{array}{l}\text { Outcomes of the APP: } \\
\text { Agricultural Sector Food } \\
\text { Security and Nutrition } \\
\text { Strategy (ASFSNS) 2016- } \\
2025 \\
\text { Inter-Ministerial } \\
\text { Agriculture/Nutrition } \\
\text { Working Group (IANWG) }\end{array}$ \\
\hline & & & $\begin{array}{l}\text { National } \\
\text { Agricultural Seeds } \\
\text { Council (NASC) } \\
\end{array}$ & & \\
\hline \multirow[t]{2}{*}{$\begin{array}{l}3 \\
4\end{array}$} & \multirow[t]{2}{*}{$\begin{array}{l}\text { Industry, } \\
\text { Trade and } \\
\text { Investment } \\
\text { (FMITI) }\end{array}$} & $\begin{array}{l}\text { World Trade } \\
\text { Organization } \\
\text { (WTO)/ } \\
\text { Sanitary and } \\
\text { Phyto-sanitary } \\
\text { Standards (SPS) }\end{array}$ & $\begin{array}{l}\text { Standards } \\
\text { Organization of } \\
\text { Nigeria (SON) }\end{array}$ & & $\begin{array}{l}\text { SON is the Codex Contact } \\
\text { Point (CCP) in Nigeria. }\end{array}$ \\
\hline & & $\begin{array}{l}\text { Federal Produce } \\
\text { Inspection } \\
\text { Services (FPIS) }\end{array}$ & $\begin{array}{l}\text { Federal } \\
\text { Competition and } \\
\text { Consumer } \\
\text { Protection } \\
\text { Commission } \\
\text { (FCCPC) } \\
\end{array}$ & & $\begin{array}{l}\text { FPIS assesses agricultural } \\
\text { exports for quality, } \\
\text { weight, fumigation and } \\
\text { packaging (QWFP). }\end{array}$ \\
\hline \multirow[t]{2}{*}{4} & \multirow[t]{2}{*}{$\begin{array}{l}\text { Environment } \\
\text { (FME) }\end{array}$} & & $\begin{array}{l}\text { National } \\
\text { Environmental } \\
\text { Standards and } \\
\text { Regulations } \\
\text { Enforcement } \\
\text { Agency (NESREA) }\end{array}$ & \multirow[t]{2}{*}{$\begin{array}{l}\text { The National } \\
\text { Policy on the } \\
\text { Environment } \\
\text { (Revised 2016) }\end{array}$} & \\
\hline & & & $\begin{array}{l}\text { Environmental } \\
\text { Health Officers } \\
\text { Registration } \\
\text { Council of Nigeria } \\
\text { (EHORECON). }\end{array}$ & & \\
\hline 5 & $\begin{array}{l}\text { Science and } \\
\text { Technology } \\
\text { (FMST) }\end{array}$ & & $\begin{array}{l}\text { National } \\
\text { Biotechnology } \\
\text { Development } \\
\text { Agency (NABDA) }\end{array}$ & & $\begin{array}{l}\text { National Biosafety } \\
\text { Management Agency Act } \\
2015\end{array}$ \\
\hline
\end{tabular}




\begin{tabular}{|c|c|c|c|c|}
\hline & & $\begin{array}{l}\text { Federal Institute of } \\
\text { Industrial Research } \\
\text { Oshodi (FIIRO) }\end{array}$ & & \\
\hline & & $\begin{array}{l}\text { Sheda Science and } \\
\text { Technology } \\
\text { Complex } \\
\text { (SHESTCO). }\end{array}$ & & \\
\hline & & $\begin{array}{l}\text { Raw Materials } \\
\text { Development and } \\
\text { Research Council } \\
\text { (RMRDC), }\end{array}$ & & \\
\hline & & $\begin{array}{l}\text { Nigerian Council of } \\
\text { Food Science and } \\
\text { Technology } \\
\text { (NiCFoST). }\end{array}$ & & \\
\hline 6 & $\begin{array}{l}\text { Budget and } \\
\text { National } \\
\text { Planning }\end{array}$ & & $\begin{array}{l}\text { The National } \\
\text { Food and } \\
\text { Nutrition Policy } \\
\text { (2016) }\end{array}$ & $\begin{array}{l}\text { The FMBNP is not among } \\
\text { the core } 5 \text { ministries with } \\
\text { a mandate for food safety. }\end{array}$ \\
\hline
\end{tabular}

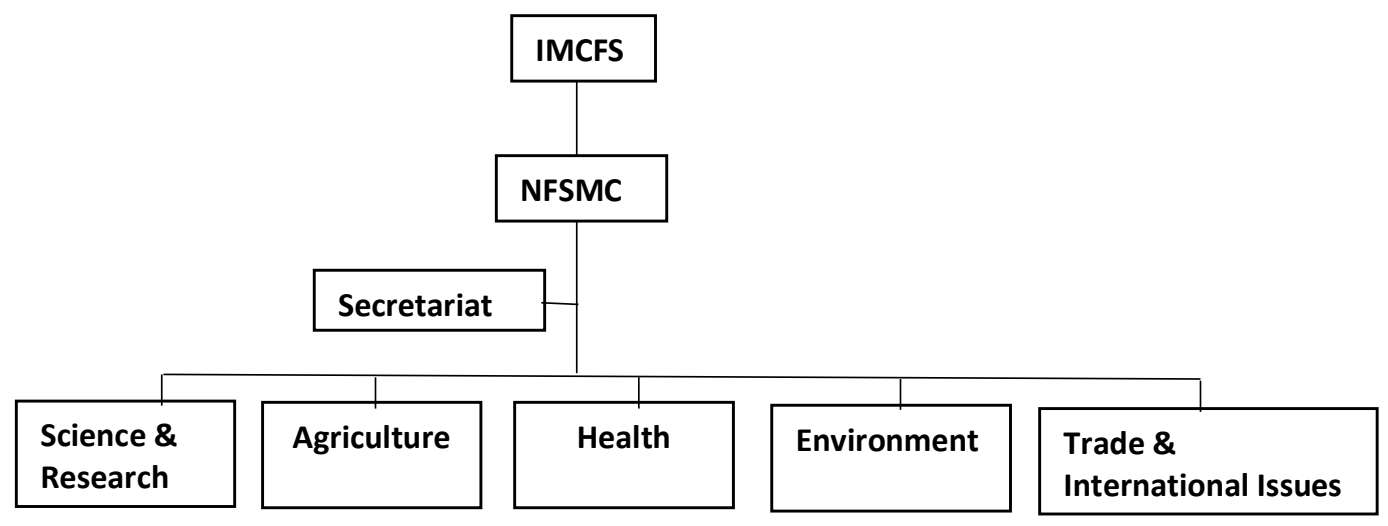

